\title{
Behavioral inhibition at five years is predicted by a short questionnaire in infancy
}

\author{
Eva Möhler* and Franz Resch \\ Department of Child and Adolescent Psychiatry, University of Heidelberg, Germany
}

\begin{abstract}
Background: Behavioural Inhibition (BI) has been identified as a risk factor for anxiety disorders and depression in childhood, adolescence and even adulthood. Focusing on early identification of developmental risk factors, this study examined the question whether short maternal report of child behaviour by questionnaire during early infancy and early toddlerhood is related to laboratory assessed BI at preschool age.

Method: 89 healthy mothers and their children, recruited from local obstetric units, were examined at three different time points: at 4 months ( $\mathrm{t} 1$ ), 14 months ( $\mathrm{t} 2$ ), and 68 months of age ( $\mathrm{t} 3$ ). The Infant Behaviour Questionnaire (IBQ) was presented at $\mathrm{t} 1$ and $\mathrm{t} 2$. Child behavioural inhibition was assessed at $\mathrm{t} 3$ in an extensive laboratory procedure.

Results: Preschoolers' BI at 68 months was strongly associated with infant distress to novelty as measured by the IBQ at $\mathrm{t} 2(p=.01)$ and even at $\mathrm{t} 1(p=.01)$. Distressto-limitations, smile/laughter, activity, and sooth ability subscores of the IBQ in infancy and toddlerhood showed - corresponding our predictions - no correlation with $\mathrm{BI}$ in preschool age.

Conclusions: Behavioural inhibition, as a potential risk factor for childhood shyness and anxiety, can be predicted by maternal judgment of infants and toddlers distress to novelty at 4 and 14 months of age. The 13 items from the IBQ-subscale "distress to novelty" therefore might be used as an easily applicable instrument in paediatrician offices to screen for infants and toddlers presumably at risk for childhood anxiety disorders. The easy identification of infants with high BI scores will be a first step to a selective and specific early intervention program of anxiety disorders.
\end{abstract}

\section{Introduction}

Behavioral Inhibition (BI) as temperamental trait is defined as the consistent tendency to show marked behavioural restraint, cautiousness or fearfulness with unfamiliar people, objects, places, new situations, or challenging events $[1,2]$. Inhibited children "are consistently shy, cautious, and emotionally reserved when they confront unfamiliar persons or contexts" [3]. Overly disinhibited children however have been proposed to be prone to disorders of impulsivity, addiction or emotional dysregulation [4].

Early onset of BI seems to have a biological basis. Moehler demonstrated that even infants BI at 4 months of age is a significant predictor of $\mathrm{BI}$ in the second year of live [5].

BI has moderate longitudinal stability from toddlerhood to childhood. Kagan, et al. for example, found the BI index at $7 \frac{1}{2}$ years significantly correlated with indices of BI at 21 months $(r=0.67 ; \mathrm{p}<$ .001) $[1,6,7]$.

BI in early childhood may be a precursor of later social withdrawal, which may lead to peer rejection in middle childhood, in turn aggravating inhibited behaviour. BI in toddlerhood is an established predictor for social phobia, shyness and affective disorders in later childhood, adolescence and early adulthood [3,8-16]. Therefore, identification of infants and toddlers at risk (with high BI scores) can be a first step towards a selective prevention and early intervention programs of anxiety disorders [17].

The causes and development of these early and enduring temperamental differences in $\mathrm{BI}$ are still not known. Children with high
BI scores are more likely to be born in a family with one or both parents affected by an anxiety disorder [18]. A child with BI and a parent with panic disorder has a higher risk for a specific polymorphism in the region of the corticotrophin releasing hormone (CRH) gene [19]. In addition, specific loci on the glutamic acid decarboxylase gene has been shown to be moderately linked to BI in mice [20].

Differences in BI are due to variations of neural circuit excitability of the limbic system, in particular of the amygdala, which is involved in the generation of fear $[1,3,21]$. One recent MRI study demonstrated amygdala activity in response to novel face stimuli. Adults with BI as toddlers showed increased bilateral activation of the amygdala in response to novel faces compared to adults who initially had been categorized as uninhibited [22].

This limbic excitability is associated with a higher heart rate in response to unfamiliarity [23]. A right frontal EEG asymmetry has also been shown to be associated with BI [1]. Children with high BI-Scores at 4 years of age produce greater right frontal EEG asymmetry at 9 and 14 months of age than children who were to become less inhibited [24].

*Correspondence to: Eva Möhler, Department of Child and Adolescent Psychiatry, University of Heidelberg, Germany, Tel: 49/680592820; E-Mail: eva. moehler@med.uni-heidelberg.de

Key words: anxiety, behavioural inhibition, child development, fears, individual differences, personality, temperament

Received: November 02, 2018; Accepted: November 10, 2018; Published: November 14, 2018 
Furthermore, an association with hair and eye color has been reported, pointing to a biological component of BI $[25,26]$.

Thus, different and complex laboratory assessment methods of behavioral inhibition have become established tools to assess BI as a disposition and precursor for shyness and anxiety in later life. Laboratory tasks and methods as mentioned above (e.g., molecular genetics, EEG, fMRI) - and behaviourally oriented lab methods (applied in this work in preschool age) use standardized stimuli and contexts, are replicable, can be coded using objective criteria and provoke the target behavior (such as fear) that are normally expressed at a lower rate in everyday naturalistic settings. Lab tasks and methods require considerable time and expense and are possibly lower ecological valid. A further objection to lab assessment includes the need of practicability, simplicity and brevity of assessing methods in daily clinical patient contact.

In contrast to standardized laboratory measures, therefore, a simple tool to identify children at risk would be preferable. Parent report measures have the advantage of assessing items in longer intervals of behavior in multiple contexts than a brief laboratory observation. They are efficient and economical [27].

However, the ability of parent report measures to identify predictors of behavioural inhibition in early infancy have not been studied, although reliable and valid screening instruments for the assessment of BI are urgently needed [28].

In this study, Infant Behavior Questionnaire is used as a parent and caregiver report measure designed to assess various aspects of infant temperament during the first year of life [29]. This questionnaire is based on temperamental theory of Derryberry, et al. wherein temperament is characterized as constitutionally based individual differences in reactivity and self-regulation [30].

Aspects of temperament examined by the IBQ are distress to novelty, soothability, distress to limitations, motor activity, and smiling/laughter. Caregivers are asked to report the relative frequency of concrete infant reactions in specific situations (feeding, sleeping, play, bathing and dressing, daily activities) during the previous week. Reliability, convergent validity, and relative stability have been demonstrated for the American and German versions of the instrument [31-34].

The age of onset for anxiety disorders usually begins in childhood. In contrast, most patients with anxiety disorders do not access treatment until well into adulthood. Typically, patients suffer for many years before receiving help, although highly effective treatments for anxiety disorders exist [17]. Weisz, et al. [35] found in a large metaanalysis effect sizes from .60 to .66 for the treatment of "Phobias/anxiety" and "Social withdrawal"

Rapee, et al. [17] describes that there is actually little information about the value of universal preventive interventions for anxiety disorders. The important question, whether temperamental precursors of fear and shyness in early infancy and early toddlerhood are related to preschool BI remains unclear.

A strong prediction of maternal report of infant distress to novelty at four months of age (based on maternal reports) highly predict the standard laboratory procedure of BI in early toddlerhood (14 months of age) in a longitudinal study of 101 children [36].

Because easy and early identification of children at risk for later anxiety disorders would be crucial for prevention and early intervention, the aim of this study was to assess the appropriateness of a specific parent report measure of infant temperament (IBQ-Subscale "Distress to novelty") in early infancy and early toddlerhood to predict later laboratory assessed BI in the 6th year of life.

\section{Method}

\section{Participants}

The sample of this study consisted of a volunteer sample of healthy Caucasian mothers and their infants after singleton pregnancies, recruited in four major local obstetric units, which attract a mixed urban and rural population. Eligibility criteria were full-term deliveries and infant weight above 2,500 g, Apgar Scores > 7 and good health of the baby as documented by the first, second, and third postnatal exam. Exclusion criteria were inability of the mother to speak and read German language, acute maternal psychiatric disorder, as well as the use of drugs or medications posing a risk to the foetus and/or excessive smoking ( $>5$ cigarettes/day) or alcohol consumption during pregnancy. Written informed consent was obtained from all participants.

Power calculation had determined a sample size of 100 motherinfant pairs. Out of 114 mothers who decided to take part in the study, 13 dropped out before study inclusion, so that 102 mother-infant pairs finally were included. After study inclusion one mother decided not to continue with the study after the first assessment, so that 101 mother-infant pairs completed the study first study phase (child at 14 months of age). Out of these, 89 were re-examined at 68 months of age and examined for behavioural inhibition in the standard international laboratory procedure. The drop-out of 12 mother-child pairs between 14 and 68 months of age was due to family relocation and impossibility or given time shortage to re-establish contact (11 cases). One mother was deceased.

\section{Study Design}

The results described in this study are part of a larger German longitudinal study about the development of BI as a temperamental trait in a non-clinical, community based sample [36,37]. The subjects were seen when the infant was 4 months (time point t1), 14 months (time point $\mathrm{t} 2$ ), and 68 months of age (time point $\mathrm{t} 3$ ). Socioeconomic status, pre- and perinatal data, medical pregnancy complications and maternal and paternal personality were documented at the first assessment. Infant health status was assessed at every visit. The Infant Behavior Questionnaire was completely filled out at 4 months and all subscales (with the exception of "distress to limitations") at 14 months of age. Behavioral inhibition was assessed in a laboratory procedure at 68 months of age. Mothers brought their infants to the laboratory during daytime, when the infants were alert, fed, and rested.

\section{Measures}

Infant Behavior Questionnaire: The IBQ was chosen to measure temperament because it is one of the most widely used parent report measures of temperament. It emphasizes individual differences in discrete categories of temperament and shows good internal consistency and discriminate validity $[13,38]$.

There is substantial evidence for external validity of the IBQ scales. They converged to a moderate degree with similar behaviors recorded during home observations [34]. Moreover, conceptually related scales from other questionnaires converge with the IBQ. For example, maternal report on the IBQ distress-to-novelty scale correlated -.69 with the RITQ Approach Scale and .61 with Bates' Infant Characteristics Questionnaire Unadaptability Scale, two of 
the other widely used measures of infant fearfulness [39]. Similar convergent validity correlations ( -0.73 and 0.76 , respectively) emerged from corresponding teacher-report data [13]. Interrater reliability is acceptable [40].

The IBQ assesses infant temperament in 78 items on 5 subscales. The questionnaire asks about frequency of certain behaviours in specific situations (sleeping, bathing, feeding, etc.) during the preceding week in order to minimize the chance of distorted maternal perceptions to influence maternal judgment. The internal consistency and independence of the five scales in the German version of the questionnaire are satisfactory. The stability coefficients of the German version correspond to a good degree with those of the American version of the IBQ scales [41].

The subscale smiling/laughter (from the child in any situation) consists of 13 items. The subscale distress to limitations (while waiting for or refusing a food, being dressed or undressed or prevented access to a desired object) has 15 items. The subscale distress to novelty (sudden changes in stimulation or avoidance toward a novel object) consists of 13 items. The subscale motor activity (gross motor activity of arms and legs) has 12 items. The soothability subscale (reduction of distress or crying when the caretaker uses soothing techniques) consists of 9 items.

Lab assessed Behavioural Inhibition at 68 months: As children get older, there is a shift in focus of the lab assessment of BI with a greater emphasis on the child's response to unfamiliar peers. Children were invited to come to the laboratory in the afternoon. Two motherchild pairs from the same study, who did not formerly know each other, were asked to enter an empty room with a carpet and two chairs located each in a corner opposite the other. Pairs were chosen to have children of the same gender in pairs. Mothers were asked to sit on the chairs and fill in questionnaires while the children were invited to sit in the middle of the room and play on a carpet with some gender appropriate toys located there. After a few minutes an attractive toy was placed in the middle of the carpet and it was coded, who grabbed it first. Then, a clown entered the room, told and invited the children to play with him. The whole procedure lasted 20 minutes. Throughout the entire episode, a number of dependent variables were coded, which includes different measures of behavioural inhibition: "latency-to-speak" means the time span (in seconds) before the child make a verbalisation to the second, before unknown child of same age and gender.

This variable ranged from 0 to 1200 seconds (20 min duration of lab BI procedure). The mean "latency-to-speak" was $344.5 \mathrm{sec}(\mathrm{SD}=$ 465) and skewness $=1.04$. The Shapiro-Wilk-test resulted in $\mathrm{W}=.70$ with $\mathrm{p}<.001$.

"proximity-to-the-mother" means the time (in sec) the child remained in the unknown play situation in the direct proximity (max. distance of 0.5 metres) to the mother.

This variable ranged from 0 to 1200 seconds (duration of lab BI procedure). The mean "proximity-to-the-mother" was $203 \mathrm{sec}$ (SD = 336) and skewness $=1.87$. The Shapiro-Wilk-test resulted in $\mathrm{W}=0.65$ with $\mathrm{p}<0.001$.

A 4-step "observation index" [23]. Two independent and beforehand trained raters coded the childs inhibited behaviour from 1 (spontaneous, inconspicuous, not anxious behaviour) to 4 (speaks not or hardly not, is not or hardly not involved in the play situation).

This variable ranged from 1 to 4 . The mean "observation index" score was $1.67(\mathrm{SD}=0.87)$ and skewness $=1.21$. The Shapiro-Wilk-test resulted in $\mathrm{W}=.74$ with $\mathrm{p}<0.001$. "index-of-inhibition" is a complex composite measurement of this three variables and in addition two further variables: "negation-of-theplay-session" (time in seconds, the child look away, stay non-involved or leave the play ground) and "frozen-watchfulness" (time in seconds, the child stays mutely and motionless in the play situation and observe at all events from the eye angle). All five variables have additionally influence on the index-of-inhibition, which ranged from 1 (low) to 10 (high).

The mean "index-of-inhibition" was $1.4(\mathrm{SD}=2.06)$ and skewness $=2.1$. The Shapiro-Wilk-test resulted in $\mathrm{W}=0.70$ with $\mathrm{p}<0.001$.

Interrater-reliability was calculated by double coding of a subgroup of 20 cases. The reliability (Cohes's Kappa) was high and toted up to 0.99 (for "latency-to-speak"), .98 (for "proximity-to-mother" and "observation index") and 0.85 for "negation-of-the-play-session". The reliability of "frozen-watchfulness" couldn't be calculated for lack of cases in the subgroup [42].

\section{Results}

\section{Sample}

At $t 3$ preschool age, the remaining mothers had a mean age of 39.6 years $(\mathrm{SD}=4.05)$ and ranged between the ages of 25 and 51 years. 82 $\%$ of the mothers were married, $17 \%$ unwed and 1 mother divorced. Some $91 \%$ lives in partnership, $8 \%$ were separated, one mother was widowed. $54 \%$ of the preschoolers were boys, $46 \%$ were girls. Some $57.3 \%$ of the mothers had at least a college degree; 20.2 had \% a high school degree. Some $50.6 \%$ were firstborns, $36 \%$ had one sibling and $12.3 \%$ had two ore more siblings. This sample is representative of a small town with a large university and a high percentage of high income, high education families. Descriptive sample data and further descriptive information at $\mathrm{t} 1$ is noticed in Moehler, et al. [5], at $\mathrm{t} 2$ in Marysko, et al. [36].

\section{Covariates}

In table 1 , the impact of socio-demographic variables on two BI-Scores is shown. Maternal education $(\mathrm{F}(2,86)=0,11 ; \mathrm{p}=.889)$ and sibling position $(\mathrm{F}(2,86)=0,14 ; \mathrm{p}=.863)$ has no relation to $\mathrm{BI}$ (statistical values indicted for "index-of-inhibition") as assessed by Anova (Table 1).

However, gender has a strong impact on preschoolers BI-score at 68 months of age: for index-of-inhibition $\mathrm{F}(1,83)=4,62 ; \mathrm{p}=.034$ and for observational rating score $\mathrm{F}(1,83)=11,08 ; \mathrm{p}<.001$ for with a higher score for female than for male preschoolers.

Maternal and paternal personality characteristics were assessed at 2 weeks by the NEO-FFI $[43,44]$, a 60 -item questionnaire assessing five dimensions of personality (extroversion, openness, conscientiousness, agreeableness, and neuroticism). The Big Five Maternal and paternal personality characteristics had no statistically significant relation to childs behavioural inhibition at 68 months of age as tested by Spearman Correlations.

\section{Infant Behavior Questionnaire:}

For the sample of 89 children remaining for examination of behavioral inhibition in preschool age, all mothers completed the IBQ subscales. The mean scores and standard deviations for the IBQ-subscales at t1 (4 months of age) and t2 (14 months of age) are specified in table 2. A strong correlation was found between the four IBQ Subscales measured at 4 and 14 months of age. 
According to our principal hypothesis of the study, in maternal judgement

"distress to novelty" at 4 months of age in parent evaluation was significantly associated with the lab assessed BI "observation index" and the "global index-of-inhibition" of the preschoolers at 68 month of age (Table 3 ).

"distress to novelty" at 14 months of age in parent evaluation was significantly associated with all lab assessed BI variables at 68 months of age: latency-to-speak, proximity-to-the-mother, observation index and the global index-of-inhibition of the preschoolers (Table 4).

The smiling/laughter, distress-to-limitations, soothability and motor activity-dimensions at were not related to BI at 68 months of age.

For the significant covariate "gender" in BI-Score at 68 months of age, we calculated possible gender effects in the IBQ-Scales at 4 and 14 months of age with the Mann-Whitney U-test. There was no gender difference in any IBQ-Subscale at 4 and 14 months of age.

Table 1. Mean and SD of BI-rating score and index-of-inhibition for socio-demographic Variables. ${ }^{1} p$-value is the result of analysis of variance relating the fear score as dependent variable with sociodemographic categories

\begin{tabular}{|c|c|c|c|c|c|c|c|}
\hline & \multicolumn{3}{|c|}{ Observation rating Score } & \multicolumn{3}{|c|}{ Index-of-inhibition } & \multirow[t]{2}{*}{$\mathbf{n}$} \\
\hline & Mean & SD & $p^{l}$ & Mean & SD & $p^{I}$ & \\
\hline Gender & \multicolumn{2}{|c|}{$\mathrm{F}(1,83)=11,08$} & $<0.001$ & \multicolumn{2}{|c|}{$F(1,83)=4,62$} & 0.034 & \\
\hline Male & 1.39 & 0.791 & & 0.97 & 2.098 & & 48 \\
\hline Female & 2.00 & 0.866 & & 1,90 & 1.921 & & 41 \\
\hline Maternal Education & \multicolumn{2}{|c|}{$\mathrm{F}(2,86)=0,34$} & 0.711 & \multicolumn{2}{|c|}{$\mathrm{F}(2,86)=0,11$} & 0.889 & \\
\hline High school & 1.75 & 1.019 & & 1.50 & 2.259 & & 20 \\
\hline College & 1.77 & 0.942 & & 1.55 & 2.525 & & 18 \\
\hline University Degree & 1.60 & 0.801 & & 1.31 & 1.827 & & 51 \\
\hline Number of siblings & \multicolumn{2}{|c|}{$\mathrm{F}(2,86)=0,941$} & 0.393 & \multicolumn{2}{|c|}{$\mathrm{F}(2,86)=0,14$} & 0.863 & \\
\hline 0 & 1.64 & 0.829 & & 1.31 & 2.054 & & 45 \\
\hline 1 & 1.81 & 0.931 & & 1.56 & 1.998 & & 32 \\
\hline 2 and more & 1.41 & 0.900 & & 1.33 & 2.386 & & 12 \\
\hline Total sample & 1.67 & 0.876 & & 1.40 & 2.060 & & 89 \\
\hline
\end{tabular}

Table 2. Means and SD of IBQ Scales in infancy (4 months of age; mother rating) and their correlation to the IBQ Scales in toddlerhood (14 months of age)

\begin{tabular}{|c|c|c|c|c|c|c|}
\hline \multirow{2}{*}{$\begin{array}{l}\text { Infant Behavior } \\
\text { Questionnaire }^{3}\end{array}$} & \multicolumn{2}{|c|}{ at 4 months of age } & \multicolumn{2}{|c|}{ at 14 months of age } & \multicolumn{2}{|c|}{ correlation } \\
\hline & Mean & SD & Mean & SD & $\mathbf{r}^{1}$ & $p^{2}$ \\
\hline Smiling/laughter & 4.03 & 0.99 & 4.97 & 0.86 & 0.568 & $<0.001$ \\
\hline Distress to limitations & 2.91 & 0.78 & --- & --- & --- & --- \\
\hline Distress to novelty & 2.09 & 0.67 & 2.14 & 0.57 & 0.388 & $<0.001$ \\
\hline Soothability & 4.65 & 0.88 & 4.52 & 1.07 & 0.505 & $<0.001$ \\
\hline Motor activity & 3.07 & 0.65 & 3.19 & 0.60 & 0.411 & $<0.001$ \\
\hline
\end{tabular}

${ }^{1}$ spearman rank correlation coefficient.

${ }^{2} p$-values indicated the probability the given correlation is distinct to a zero correlation.

${ }^{3}$ the IBQ-subscale "distress to limitations" was not measured at 14 months of age.

Table 3. Means and SD of IBQ Scales in infancy (4 months of age; mother rating) and their correlation with four different BI-Variables in the $6^{\text {th }}$ year of life (68 months of age; lab assessed)

\begin{tabular}{|c|c|c|c|c|c|c|c|c|}
\hline \multirow{2}{*}{$\begin{array}{l}\text { Infant Behavior } \\
\text { Questionnaire at } 4 \\
\text { months of age }\end{array}$} & \multicolumn{2}{|c|}{ Latency-to-speak } & \multicolumn{2}{|c|}{ Proximity-to-mother } & \multicolumn{2}{|c|}{$\begin{array}{c}\text { Observation } \\
\text { Rating Score }\end{array}$} & \multicolumn{2}{|c|}{ Index-of-inhibition } \\
\hline & $\mathbf{r}^{1}$ & $p^{2}$ & $\mathbf{r}^{1}$ & $p^{2}$ & $\mathbf{r}^{1}$ & $p^{2}$ & $\mathbf{r}^{1}$ & $p^{2}$ \\
\hline Smiling/laughter & 0.052 & 0,627 & 0.020 & 0.848 & 0.007 & 0.941 & -0.085 & 0.423 \\
\hline Distress to limitations & -0.014 & 0.891 & -0.112 & 0.294 & -0.043 & 0.685 & -0.038 & 0.723 \\
\hline Distress to novelty & 0.185 & 0.082 & 0.101 & 0.344 & 0.312 & 0.002 & 0.329 & 0.001 \\
\hline Soothability & -0.029 & 0.782 & 0.085 & 0.427 & 0.057 & 0.594 & 0.064 & 0.549 \\
\hline Motor activity & 0.051 & 0.630 & 0.076 & 0.474 & 0.011 & 0.912 & 0.070 & 0.511 \\
\hline
\end{tabular}

${ }^{1}$ spearman rank correlation coefficient.

${ }^{2} p$-values indicated the probability the given correlation is distinct to a zero correlation.

Table 4. Means and SD of IBQ Scales in toddlerhood (14 months of age; mother rating) and their correlation with four BI-Variables in the $6^{\text {th }}$ year of life (68 months of age; lab assessed)

\begin{tabular}{|c|c|c|c|c|c|c|c|c|}
\hline \multirow{2}{*}{$\begin{array}{l}\text { Infant Behavior } \\
\text { Questionnaire at } 14 \\
\text { months of age }\end{array}$} & \multicolumn{2}{|c|}{ Latency-to-speak } & \multicolumn{2}{|c|}{ Proximity-to-mother } & \multicolumn{2}{|c|}{$\begin{array}{c}\text { Observation } \\
\text { Rating }\end{array}$} & \multicolumn{2}{|c|}{ Index-of-inhibition } \\
\hline & $\mathrm{r}^{1}$ & $\mathrm{p}^{2}$ & $\mathrm{r}^{1}$ & $p^{2}$ & $\mathrm{r}^{1}$ & $p^{2}$ & $\mathrm{r}^{1}$ & $p^{2}$ \\
\hline Smiling/laughter & -.041 & 0.700 & .044 & 0.682 & .021 & 0.840 & -.049 & 0.650 \\
\hline Distress to novelty & .246 & 0.021 & .244 & 0.022 & .290 & 0.006 & .344 & 0.001 \\
\hline Soothability & -.065 & 0.544 & -.036 & 0.734 & .011 & 0.919 & -.052 & 0.629 \\
\hline Motor activity & .031 & 0.771 & -.054 & 0.617 & -.025 & 0.813 & -.033 & 0.757 \\
\hline
\end{tabular}

${ }^{1}$ spearman rank correlation coefficient.

${ }^{2} p$-values indicated the probability the given correlation is distinct to a zero correlation.

${ }^{3}$ the IBQ-subscale "distress to limitations" was not measured at 14 months of age. 


\section{Discussion}

The data presented above indicate a statistically significant association between maternal judgment of infant distress to novelty in the 1st year of life and behavioral inhibition assessed in a laboratory procedure in preschool age.

The association is not strong, but significant for several dependent variables. And it is found in spite of not taking in account multiple other relevant factors, e.g. the attachment quality of the child to the mother, the mothers insensitivity or education style.

This effect was not mediated by maternal personality or maternal education as covariates.

It might be postulated that maternal judgment of infant temperament with the Infant Behavior Questionnaire seems to be an appropriate measure with regard to the detection of early signs of distress to novelty in preschool age.

The correlation between the measured IBQ- scales at 4 and 14 months of age demonstrate stability of the IBQ-subscales. This stability demonstrates the reliability of the IBQ in infancy and early toddlerhood in predicting laboratory assessed $\mathrm{BI}$ in preschool age.

These data indicate that mothers of a community sample seem to be able to detect their infants' distress to novelty at an early stage and that these judgments correspond to laboratory assessments of distress to novelty as much as more than 5 years later.

Distress to novelty or behavioral inhibition is an established predictor for anxiety proneness during later childhood [4,8,9,45,46]. Therefore these data provide evidence for the aptitude of the distressto-novelty IBQ subscale as an early screening tool to identify infants at risk for developing anxiety disorders. This instrument is easily accepted by parents and caregivers and with 13 items conveniently short in application. It can be applied in a short office visit (e.g. during waiting time) and used for clinical as much as scientific purposes.

Validity of the instrument has been discussed extensively by Pauli-Pott, et al. [47], Marysko, et al. [36]. As all parental report questionnaires, the IBQ might be subject to perceptional distortion. Such a distortion is likely, when mothers are depressed or anxious. Pauli-Pott, et al. [47] was able to show, that depressed mothers do tend to judge their infants as having more distress to novelty. On the other hand, Marysko, et al. [36] demonstrated, that this judgment was nonetheless accurate, as mothers with depression do have children with higher levels of distress to novelty. Therefore maternal judgment can be regarded as moderately accurate in the IBQ, because the IBQ asks for frequencies of certain types of behavior, not interpretation of childrens actions and can therefore gather somewhat objective informations.

As anxiety disorder and childhood shyness constitutes a major developmental risk, early detection of risk factors seem crucial for identifying targets of prevention. The results of this study lead to the proposition of a wider application of the Infant behaviour Questionnaire in Clinical practice and routine office visits in infancy in order to detect early signs of risks for mental illness that might be used in preventional efforts.

\section{Limitations}

The study sample was community based. Therefore this study does no permit conclusions about clinical populations, because judgment of infant temperament might be distorted or biased by more severe parental psychopathology.
At preschool age, laboratory assessed BI was measured, but no anxiety disorder diagnosis was given.

This study also does not permit statements about a genetic or environmental influence on infant behavior.

The influence of other biases on the parent reports including social desirability and retrospective recall was not controlled.

\section{Clinical implications}

High scores on the distress-to-novelty scale imply a risk for later behavioral inhibition according to the data presented above. With behavioral inhibition being a relatively stable personality trait that puts children at risk for anxiety disorder, early tools for intervention are highly important in order to identify precursors and prevent childhood emotional disorders.

These data might justify usage of the distress-to-novelty IBQ subscale, for the routine postnatal examinations at 3 to 4 months postnatal.

Cerebral plasticity in the 1st year of life is high [48,49]; therefore preventive interventions should be most effective when targeting infants. These data render support for application of the Infant Behavior Questionnaire as a screening tool of high efficiency in order to identify children at risk for psychopathology at a very early stage.

\section{Acknowledgments}

We thank the participating obstetric hospitals for their support.

\section{Funding}

This research was funded by the German Research Foundation (DFG: MO 978/1-1/2)

\section{References}

1. Kagan J, Reznick JS, Snidman N (1988) Biological bases of childhood shyness. Science 240: 167-171. [Crossref]

2. Asendorpf JB (1989) Shyness as a final pathway for two different kinds of inhibition. Journal of Personality and Social Psychology 57: 481-492.

3. Kagan J, Snidman N (1991) Infant predictors of inhibited and uninhibited profiles. Psychological Science 2: 40-44.

4. Rothenberger S, Resch F, Doszpod N, Moehler E (2011) Prenatal stress and infan affective reactivity at five months of age. Early Hum Dev 87: 129-136. [Crossref]

5. Moehler E, Kagan J, Oelkers-Ax R, Brunner R, Poustka L, et al. (2008). Infant predictors of behavioural inhibition. British Journal of Developmental Psychology 26: 145-150.

6. Asendorpf JB (1994) The malleability of behavioral inhibition: a study of individua developmental functions. Developmental Psychology 30: 912-919.

7. Pfeifer M, Goldsmith HH, Davidson RJ, Rickman M (2002) Continuity and change in inhibited and uninhibited children. Child Dev 73: 1474-1485. [Crossref]

8. Biederman J, Hirshfeld-Becker DR, Rosenbaum JF, Herot C, Friedman D, et al. (2001) Further evidence of association between behavioral inhibition and social anxiety in children. Am J Psychiatry 158: 1673 - 1679. [Crossref]

9. Biederman J, Rosenbaum JF, Bolduc-Murphy EA, Faraone SV, Chaloff, et al. (1993) A 3-year follow-up of children with and without behavioral inhibition. J Am Acad Child Adolesc Psychiatry 32: 814-821. [Crossref]

10. Caspi A, Moffitt TE, Newman DL, Silva PA (1996) Behavioral observations at age 3 years predict adult psychiatric disorders. Arch Gen Psychiatry 53: 1033-1039. [Crossref]

11. Hayward C, Killen J, Kraemer K, Taylor C (1998) Linking selfreported childhood behavioral inhibition to adolescent social phobia. J Am Acad Child Adolesc Psychiatry 37: 1308-1316. [Crossref] 
12. Rosenbaum JF, Biederman J, Bolduc EA, Hirshfeld DR, Faraone SV, et al. (1992) Comorbidity of parental anxiety disorders as risk for childhood-onset anxiety in inhibited children. American Journal of Psychiatry 149: 475-481. [Crossref]

13. Hirshfeld-Becker DR, Biederman J, Henin A, Faraone SV, Davis S (2007). Behavioral inhibition in preschool children at risk is a specific predictor of middle childhood social anxiety: a five-year follow-up. J Dev Behav Pediatr 28: 225-233. [Crossref]

14. Pine DS, Helfinstein SM, Bar-Haim Y, Nelson E, Fox NA (2009). Challenges in the development of novel therapeutics for the treatment of childhood central nervous system disorders. Neuropsychopharmacology 34: 213-228. [Crossref]

15. Rubin KH, Hastings PD, Stewart SL, Henderson HA, Chen X (1997) The consistency and concomitants of inhibition: some of the children, all of the time. Child Dev 68: 467-483. [Crossref]

16. Schwartz CE, Snidman N, Kagan J (1999) Adolescent social anxiety as an outcome of inhibited temperament in childhood. J Am Acad Child Adolesc Psychiatry 38: 10081015. [Crossref]

17. Rapee RM, Kennedy S, Ingram M, Edwards S, Sweeney L (2005) Prevention and early intervention of anxiety disorders in inhibited preschool children. $J$ Consult Clin Psychol 73: 488-497. [Crossref]

18. Rosenbaum JF, Biederman J, Hirshfeld DR, Bolduc EA, Faraone SV, et al. (1991) Further evidence of an association between behavioral inhibition and anxiety disorders: results from a family study of children from a non-clinical sample. J Psychiatr Res 25 : 49-65. [Crossref]

19. Smoller JW, Yamaki LH, Fagerness JA, Biederman J, Racette S, et al. (2005) The corticotrophin releasing hormone gene and behavioral inhibition in children at risk for panic disorder. Biological Psychiatry 15: 1485 - 1492. [Crossref]

20. Smoller JW, Rosenbaum JF, Biederman J, Susswein LS, Kennedy J (2001) Genetic association analysis of behavioral inhibition using candidate loci from mouse models. Am J Med Genet 105: 226-235. [Crossref]

21. Perez-Edgar K, Roberson-Nay R, Hardin MG, Poeth K, Guyer AE, et al. (2007). Attention alters neural responses to evocative faces in behaviorally inhibited adolescents. NeuroImage 35: 1538 -1546. [Crossref]

22. Schwartz CE, Wright CI, Shin LM, Kagan J, Rauch SL (2003). Inhibited and uninhibited infants "grown up": adult amygdalar response to novelty. Science 300: 1952-1953. [Crossref]

23. Kagan J (1994) Galen's Prophecy. New York: Basic Books.

24. Fox NA, Henderson HA, Rubin KH, Calkins SD, Schmidt LA (2001) Continuity and discontinuity of behavioral inhibition and exuberance: psychophysiological and behavioural influences across the first four years of life. Child Dev 72: 1-21. [Crosssref]

25. Moehler E, Kagan J, Brunner R, Wiebel A, Kaufmann C, et al. (2006a). Association of behavioral inhibition with hair pigmentation in a European sample. Biological Psychology 72: 344-346. [Crossref]

26. Rosenberg A, Kagan J (1989) Physical and physiological correlates of behavioral inhibition. Dev Psychobiol 22: 753-770. [Crossref]

27. Rothbart MK, Bates JE (1998) Handbook of Child Psychology: Social, emotional, and personality development. In Damon W, Eisenberg N (Eds) (5th Edn) Temperament 3: 105-176.

28. Bishop G, Spence SH, McDonald C (2003) Can parents and teachers provide a reliable and valid report of behavioral inhibition? Child Dev 74: 1899-1917. [Crossref]

29. Rothbart MK (1981) Measurement of temperament in infancy. Child Development 52 569-578.
30. Rothbart MK, Derryberry D (1981) Development of individual differences in temperament. In Lamb ME \& Brown AL (Eds) Advances in developmental. Psychology 1: $37-86$

31. Bridges LJ, Palmer SA, Morales M, Hurtado M, Tsai D (1993) Agreement between affectively based observational and parent-report measures of temperament at infant age 6 months. Infant Behavior and Development 16: 501-506.

32. Goldsmith HH, Rothbart MK (1991) Contemporary instruments for assessing early temperament by questionnaire and in the laboratory. In Strelau J, Angleitner A (Eds) Explorations in temperament pp. 249-272.

33. Pauli-Pott U, Mertesacker B, Beckmann D (1991) A questionnaire for the assessmen of temperament in early childhood as judged by parents. Zeitschrift für Kinder- und Jugendpsychiatrie und Psychotherapie 31: 99-110.

34. Rothbart MK (1986) Longitudinal observation of infant temperament. Developmental Psychology 22: 356-365.

35. Weisz JR, Weiss B, Han SS, Granger DA, Morton T (1995) Effects of Psychotherapy With Children and Adolescents Revisited: A Meta-Analysis of Treatment outcome studies. Psychol Bull 117: 450-468. [Crossref]

36. Marysko M, Finke P, Wiebel A, Resch F, Moehler E (2009) Can mothers predict childhood behavioural inhibition in early infancy? Child and Adolescent Mental Health 15: 91-96.

37. Möhler E, Parzer P, Brunner R, Wiebel A, Resch F (2006b). Emotional stress in pregnancy predicts human infant reactivity. Early Hum Dev 82: 731-737. [Crossref]

38. Goldsmith HH, Rieser-Danner LA, Briggs S (1991) Evaluating convergent and discriminant validity of temperament questionnaires for preschoolers, toddlers, and infants. Developmental Psychology 27: 566-579.

39. Carey WB, McDevitt SC (1978) Revision of the Infant Temperament Questionnaire Pediatrics 61: 735-739. [Crossref]

40. Lamb ME, Frodi AM, Hwang CP, Frodi ME (1983) Interobserver and test-retest reliability of Rothbart's Infant Behavior Questionnaire. Scand J Psychol 24: 153-156. [Crossref]

41. Pauli-Pott U, Mertesacker B, Beckmann D (2004) Predicting the development of infant emotionality from maternal characteristics. Dev Psychopathol 16: 19-42. [Crossref]

42. Rehbein A (2009) Behaviorale Inhibition: trait or state? Unpublished Diploma thesis, Universität Koblenz-Landau.

43. Costa PT, McCrae RR (1985) The NEO-Personality-Inventory. Manual Form S and Form R. Odessa, Florida. Psychological Assessment Resources.

44. Borkenau P, Ostendorf F (1989) Untersuchung zum Fünf-Faktorenmodell der Persönlichkeit und seiner diagnostischen Erfassung. Zeitschrift für Differentielle und Diagnostische Psychologie 10: 239-251.

45. Hirshfeld DR, Rosenbaum JF, Biederman J, Bolduc EA, Faraone SV (1992) Stable behavioral inhibition and its association with anxiety disorder. $J$ Am Acad Child Adolesc Psychiatry 31: 103-111. [Crossref]

46. Kagan J, Snidman N (1999) Early childhood predictors of adult anxiety disorders. Biol Psychiatry 46: 1536-1541. [Crossref]

47. Pauli-Pott U, Ries-Hahn A, Kupfer J, Beckmann D (1999) Covariation of parental judgments of child behavioral characteristics with a developmental scale and observation of behaviors. Praxis der Kinderpsychologie und Kinderpsychiatrie 48: 311-325.

48. Herschkowitz N, Kagan J, Zilles K (1997) Neurobiological bases of behavioral development in the first year. Neuropediatrics 28: 296-306. [Crossref]

49. Schore AN (1994) Affect regulation and the origin of self: The neurobiology of emotional development. Hillsdale, NJ: Erlbaum.

Copyright: (C2018 Möhler E. This is an open-access article distributed under the terms of the Creative Commons Attribution License, which permits unrestricted use, distribution, and reproduction in any medium, provided the original author and source are credited. 